\title{
Common Mental Disorders and Substance Use in School Children of Eastern Nepal
}

\author{
Sharma $\mathbf{P}^{1}$, Sharma $\mathbf{P}^{2}$, Thakur $\mathbf{N}^{2}$, Sharma $\mathbf{S}^{3}$, Pokharel $\mathbf{M}^{3}$ \\ 1. Lecturer, Department of Psychiatry, Patan Academy Of Health Sciences, Lalitpur, Nepal 2. Junior \\ Resident, BPKIHS, Dharan, Nepal 3. Research Officer, Arogin Health Care And Research Centre, \\ Kathmandu, Nepal
}

E-mail *Corresponding author: pawan60@ gmail.com

\begin{abstract}
Introduction: School mental health is one of the important areas where early detection can lead to appropriate early intervention and burden of disease can be minimized. There is dearth of prevalence studies of common mental disorders on school going adolescents in Nepal. Considering this we aimed to study the prevalence of common mental health problems and substance use in school going adolescents.
\end{abstract}

Material And Method: We evaluated 240 students for common mental disorders (depression and anxiety) using translated version of PHQ-4 and substance use single validated question after taking consent from school authorities and assent from students.

Results: It was seen that $68.8 \%$ students had psychological distress. $22.9 \%$ and $27.5 \%$ of students had anxiety and depression respectively on screener and $23.3 \%$ students had use of substance at least once within a year. When compared male had significantly higher number of substance use as compared to female but no difference in PHQ-4 scores were seen when compared between gender and history of substance use.

Conclusion: The study shows the current scenario of school going adolescents in Nepal and highlights the need of prevalence data on more generalizable setting.

Keywords: School Mental Health, Prevalence, Nepal

\section{INTRODUCTION}

Child and adolescent mental health problems are a major contributor to global burden of disease and health-related disability of disease. ${ }^{1}$ Half of the cases of mental disorders develop by the age of 14 years, although most remain undetected and untreated until later in life. ${ }^{2}$ Investigating the global and country-level burden attributable to mental and substance use disorders in children and youth is important from both epidemiological and global health policy standpoint, particularly given the large proportion of children and youth living in lower and middle income countries (LMICs). ${ }^{3}$ SouthEast Asian Region with one quarter of the world's population has a significant burden of mental illness but low priority is given in most countries of the region. ${ }^{4}$ In Nepal, around $40 \%$ of the total population is 16 years or younger. ${ }^{5}$
When we look at the prevalence data, mental health problems affect $10-20 \%$ of children and only $10 \%$ of such trials come from low-income and middle-income countries. ${ }^{6}$ Nepal lacks national level prevalence data on mental disorders. $^{7}$ Another significant problem in school children is substance use. Although not well studied in lower income countries like Nepal, substance use is often initiated in adolescence and accounts for a substantial proportion of the disability burden faced by adolescents. ${ }^{8}$

It is a well-known fact that delivering mental health services through the school system can address key financial and structural barriers that often prevent children from receiving services. ${ }^{9}$ Considering the dearth of data in Nepal regarding school mental health, we aim to study the prevalence of mental health problems 
(depression and anxiety) and substance use in a school of Eastern Nepal using screening questionnaires.

\section{MATERIAL AND METHOD}

We undertook a cross-sectional study in government schools of Inaruwa municipality of Sunsari district of Nepal. All the schools of the said municipality were listed and three schools were selected randomly via lottery method. For sample size, we used the formula: Sample Size $(N)=\left(Z^{2} \times p \times q\right) / M^{2}$; where, $p=$ estimated prevalence $q=1-p, M=$ Margin of Error (0.05), $\mathrm{Z}=$ constant value $=1.96$. The estimated prevalence of $11 \%$ was taken from the recently published pilot study of Nepal. ${ }^{10}$ The calculated sample size was 150 but we wanted to include all the available adolescent students from these schools, hence, 240 students were taken. The students who were busy in school assessments were not taken. The information about the study was provided to all the students and any student not willing to participate were excluded. The identity of participants was kept confidential. However, basic awareness session of ten minutes was given to all the students about mental illnesses and drug use and were suggested to visit a mental health professional if they had significant problem. All of the students in class 9, 11 and 12 were willing to take part in the study. Whole of class 10 was excluded as they were busy in schools' assessment. The permission for the study was taken from the principal of each school. Assent was taken from the students. The ethical clearance was taken from the departmental research unit under institutional review committee of B.P. Koirala Institute of Health Sciences, Dharan, Nepal. The data collection was conducted between the periods of $12^{\text {th }}$ December 2017 to $24^{\text {th }}$ December 2017.

Tools Used:

i. Demographic Profile: Basic demographic details like age, gender, religion, education etc. were taken using the semi-structured proforma.

ii. PHQ-4: This four-item scale consists of two core criteria each for depressive disorder and generalized anxiety disorder and is regarded as ultra-brief tool for detection of depression and anxiety. ${ }^{11}$ PHQ-4 total score ranges from 0 to 12, with categories of psychological distress being: None: 0-2; Mild: 3-5; Moderate: 6-8; Severe: 9-12. On each depression and anxiety subscale, a score of 3 or greater is considered positive for screening purposes. Study from general population support the reliability and validity of this scale. ${ }^{12}$ It also has good reliability and validity in young adults and has a potential to be used as a mass screener for depression and anxiety in this group. ${ }^{13}$

iii. Drug Use question: This is a single question asked to the participants. "How many times in the past year have you used an illegal drug or used a prescription medication for nonmedical reasons?" A response of at least 1 time is considered positive for drug use. ${ }^{14}$ This single question has been found to be effective in accurately identifying drug use especially in primary care. ${ }^{15}$ In our study we described to the students while taking consent that use of any kind of substance like tobacco, alcohol, cannabis or opioids should also be taken as drug use. This was enlisted in the Nepali version of questionnaire as well.

Both the tools were translated into Nepali language using the WHO method ${ }^{16}$ consisting of (a) establishment of a bilingual group of experts,

(b) examination of the conceptual structure of the instruments by the experts, (c) translation, (d) examination of the translation by the experts, (e) examination of the translation by a monolingual group, (f) blind back- translation and (g) examination of the blind backtranslation by the experts.

\section{RESULT}

As seen in table 1, the mean age for the participants was 16.66 years ( $\mathrm{SD}=1.79$ years). Among the students, majority $(61.7 \%)$ were

male. Maximum number of students (96.3\%) followed Hinduism. 90, 93 and 57 students were in class 9, 11 and 12 respectively. The PHQ-4 scores showed around half $(49.6 \%)$ students to have mild symptoms and $16.7 \%$ and $2.5 \%$ had moderate and severe symptoms respectively. $22.9 \%$ of students were screen positive for anxiety and $27.5 \%$ were screen positive for depression. Among the students $23.3 \%$ had a history of drug use. When compared between males and females, it was seen that the history 
of drug use was significantly more in males as compared to females $(p=0.01)$. However, the PHQ-4 scores compared between male and female using Mann-Whitney $U$ test showed no difference $(p=0.60)$. Similarly, there was no difference in PHQ-4 scores when compared between drug users and non-users.

Table 1: Socio-demographic Profile, PHQ-4 and Substance Use

\begin{tabular}{|l|l|}
\hline Age (years) & $16.66(\mathrm{SD}=1.79)$ \\
\hline Gender & $148(61.7 \%)$ \\
Male & $92(38.3 \%)$ \\
Female & \\
\hline Religion & $231(96.3 \%)$ \\
Hindu & $8(3.3 \%)$ \\
Muslim & $1(0.4 \%)$ \\
Christian & \\
\hline Education & $90(37.5 \%)$ \\
Class 9 & $93(38.8 \%)$ \\
Class 11 & $57(23.8 \%)$ \\
Class 12 & \\
\hline PHQ4 & $75(31.3 \%)$ \\
Normal & $119(49.6 \%)$ \\
Mild & $40(16.7 \%)$ \\
Moderate & $6(2.5 \%)$ \\
Severe & \\
\hline Drug Use & $56(23.3 \%)$ \\
Yes & $173(72.1 \%)$ \\
No & $11(4.6 \%)$ \\
Didn't report & \\
\hline Screening & $55(22.9 \%)$ \\
Anxiety & $66(27.5 \%)$ \\
Depression & \\
\hline
\end{tabular}

Table 2: Gender Differences in Substance Use

\begin{tabular}{|l|l|l|l|}
\hline Gender & $\begin{array}{l}\text { Substance } \\
\text { Yes }\end{array}$ & $\begin{array}{l}\text { Substance } \\
\text { NO }\end{array}$ & $\begin{array}{l}\text { Fisher's } \\
\text { Exact } \\
\text { Significance }\end{array}$ \\
\hline Male & 44 & 103 & $\mathrm{P}=0.01^{*}$ \\
Female & 12 & 70 & \\
\hline
\end{tabular}

Table 3: Association Of Gender and substance use with PHQ-4 Score

\begin{tabular}{|l|l|l|}
\hline Variables & $\begin{array}{l}\text { Mean Rank } \\
\text { for PHQ4 } \\
\text { score }\end{array}$ & $\begin{array}{l}\text { Mann-Whitney } \\
\text { U Test }\end{array}$ \\
\hline $\begin{array}{l}\text { Gender } \\
\text { Male } \\
\text { Female }\end{array}$ & 122.31 & $\begin{array}{l}\mathrm{U}=6539.5, \mathrm{Z}=- \\
0.519 \\
\mathrm{P}=0.60\end{array}$ \\
$\begin{array}{l}\text { Drug use } \\
\text { Yes }\end{array}$ & 117.58 & $\mathrm{U}=4721, \mathrm{Z}=\quad-$ \\
No & 117.20 & 0.288 \\
& 114.29 & $\mathrm{P}=0.78$ \\
\hline
\end{tabular}

\section{DISCUSSION:}

The mean age of the school children of 16.66 years was seen with preponderance of male students. Though the census data suggest male and female ratio to be comparable $(1.02)^{5}$, the female being less in number suggests less literacy rate and higher drop outs as compared to male. The PHQ-4 data suggests total of $68.8 \%$ of the students had some psychological distress, however among them majority $49.6 \%$ had mild distress. This data is higher than prevalence data from big and robust studies ${ }^{17,} 18$ which used tools for diagnosis rather than tools for screening. It is a well-known fact that the prevalence of anxiety and depression accounts for around half of the psychiatric diagnosis in adolescent group of population ${ }^{19}$, our study using PHQ-4 has screened these two common mental health problems. The important fact to be taken into account is that we have used only the screening instrument for depression and anxiety rather than the diagnostic tools. Though the study shows the prevalence of $22.9 \%$ of anxiety and $27.5 \%$ of depression; the real prevalence is likely to be lower due to possibility of high false positive rate in absence of confirmation of diagnosis. The finding that $23.3 \%$ were screened positive for some kind of drug use using the "drug use question" is comparable to the studies done in Iran and Turkey ${ }^{20,21}$ but it was less than the study done in Nigeria. ${ }^{22}$ There was significant difference between male and female in substance use i.e. percentage of male were more as compared to female in using substance and this finding is similar to the studies done in other high school 
students. ${ }^{20}, 23$ When we looked at PHQ-4 scores there was no differences between the genders. The majority of studies show that the substance use and psychiatric illnesses have higher rate of comorbidity 24,25 , however, no difference in the PHQ-4 scores with substance use was seen in our study.

This is one of the very few studies from Nepal in school going adolescents. There are some limitations to this study. The major limitation is the use of PHQ-4 in adolescents. Though the tool has been used in young adults it has not been used among school going adolescents. The questionnaires are also not validated in the school population of Nepal. Similarly, a cross sectional application of screening instruments doesn't give a diagnosis. The school of a municipality in eastern Nepal might not be representative of all the schools of country. However, the study could play an important role in laying foundation for further studies as the findings here give some idea about the problem statement.

\section{CONCLUSION:}

The problems of mental health and substance use in school going children of Nepal is comparable to other countries worldwide. The methodology of our study could be replicated in screening the common mental disorders (anxiety and depression) and use of substance. The school mental health programs that are need of lower income countries could be initiated on the base of prevalence data like ours in future.

\section{ACKNOWLEDGEMENT: None}

\section{FUNDING: None}

\section{CONFLICT OF INTEREST: None}

\section{REFERENCES:}

1. Remschmidt H, Nurcombe B, Belfer ML, Sartorius N, Okasha A. The Mental Health of Children and Adolescents: An area of global neglect. John Wiley E Sons; 2007. 259 p. 2. Patel V, Flisher AJ, Hetrick S, McGorry P. Mental health of young people: a global public-health challenge. Lancet Lond Engl. 2007, 369(9569):1302-13.

3. Erskine HE, Moffitt TE, Copeland WE, Costello EJ, Ferrari AJ, Patton G, et al. A heavy burden on young minds: the global burden of mental and substance use disorders in children and youth. Psychol Med. 2015, 45(7):1551-63.
4. Sharan P, Sagar R, Kumar S. Mental health policies in South-East Asia and the public health role of screening instruments for depression. WHO South-East Asia J Public Health. 2017, 6(1):5-11.

5.Central Bureau of Statistics. Available from: http://www.cbs.gov.np/

6. Kieling C, Baker-Henningham H, Belfer M, Conti G, Ertem I, Omigbodun $O$, et al. Child and adolescent mental health worldwide: evidence for action. Lancet Lond Engl. 2011, 378(9801):1515-25.

7. WHO | Mental Health Atlas 2014. Available from: http://www.who.int/mental_health/evidence/atlas/mental_h ealth_atlas_2014/en/

8. Davidson LL, Grigorenko EL, Boivin MJ, Rapa E, Stein A. A focus on adolescence to reduce neurological, mental health and substance-use disability. Nature. 2015, 527(7578):S161-166.

9. Garrison EG, Roy IS, Azar V. Responding to the mental health needs of Latino children and families through schoolbased services. Clin Psychol Rev. 1999, 19(2):199-219.

10. Jha AK, Ojha SP, Dahal S, Sharma P, Pant SB, Labh S, Marahatta K, Shakya S, Adhikari RP, Joshi D, Luitel NP. Prevalence of Mental Disorders in Nepal: Findings from the Pilot Study. Journal of Nepal Health Research Council. 2019, 17(2):141-7.

11. Kroenke K, Spitzer RL, Williams JBW, Löwe B. An ultra-brief screening scale for anxiety and depression: the PHQ-4. Psychosomatics. 2009, 50(6):613-21.

12. Löwe B, Wahl I, Rose M, Spitzer C, Glaesmer H, Wingenfeld $K$, et al. A 4-item measure of depression and anxiety: validation and standardization of the Patient Health Questionnaire-4 (PHQ-4) in the general population. J Affect Disord. 2010, 122(1-2):86-95.

13. Khubchandani J, Brey $R$, Kotecki J, Kleinfelder J, Anderson J. The Psychometric Properties of PHQ-4 Depression and Anxiety Screening Scale among College Students. Arch Psychiatr Nurs. 2016, 30(4):457-62.

14. Pilowsky DJ, Wu L-T. Screening for alcohol and drug use disorders among adults in primary care: a review. Subst Abuse Rehabil. 2012, 3:25-34.

15. Smith PC, Schmidt SM, Allensworth-Davies D, Saitz R. A Single-Question Screening Test for Drug Use in Primary Care. Arch Intern Med. 2010, 170(13): 1155-60

16. Sartorius $N$, Janca A. Psychiatric assessment instruments developed by the World Health Organization. Soc Psychiatry Psychiatr Epidemiol. 1996, 31(2):55-69. 17. Costello EJ, Mustillo S, Erkanli A, Keeler G, Angold A. Prevalence and Development of Psychiatric Disorders in Childhood and Adolescence. Arch Gen Psychiatry. 2003, 60(8):837-44.

18. Ravens-Sieberer $U$, Wille $N$, Erhart $M$, Bettge $S$, Wittchen $H-U$, Rothenberger A, et al. Prevalence of mental health problems among children and adolescents in Germany: results of the BELLA study within the National Health Interview and Examination Survey. Eur Child Adolesc Psychiatry. 2008, 17 Suppl 1:22-33.

19. Merikangas KR, He J, Burstein M, Swanson SA, Avenevoli S, Cui L, et al. Lifetime Prevalence of Mental Disorders in US Adolescents: Results from the National 
Comorbidity Study-Adolescent Supplement (NCS-A). J Am Acad Child Adolesc Psychiatry. 2010, 49(10):980-9.

20. Ahmadi J, Hasani M. Prevalence of substance use among Iranian high school students. Addict Behav. 2003, 28(2):375-9.

21. Ogel K, Corapçioğlu A, Sir A, Tamar M, Tot S, Doğan $O$, et al. [Tobacco, alcohol and substance use prevalence among elementary and secondary school students in nine cities of Turkey]. Turk Psikiyatri Derg Turk J Psychiatry. 2004, 15(2):112-8.

22. Oshodi OY, Aina OF, Onajole AT. Substance use among secondary school students in an urban setting in Nigeria: prevalence and associated factors. Afr J Psychiatry. 2010, 13(1):52-7.

23. Kokkevi A, Stefanis C. The epidemiology of licit and illicit substance use among high school students in Greece. Am J Public Health. 1991, 81(1):48-52.

24. Kessler RC, Chiu WT, Demler O, Walters EE. Prevalence, Severity, and Comorbidity of 12-Month DSMIV Disorders in the National Comorbidity Survey Replication. Arch Gen Psychiatry. 2005, 62(6):617-27.

25. Armstrong TD, Costello EJ. Community studies on adolescent substance use, abuse, or dependence and psychiatric comorbidity. J Consult Clin Psychol. 2002, 70(6):1224-39. 